\title{
ACCIONES POLÍTICAS Y PROYECTOS ECONÓMICOS EN GUANAJUATO FRENTE AL CONFLICTO DE LA SIERRA GORDA 1847-1852
}

\author{
Carlos Armando Preciado de Alba
}

\begin{abstract}
Resumen: Las revoluciones europeas de 1848 inquietaron a grandes sectores de la clase política mexicana, pues fueron percibidas como un peligro para el orden social. Asimismo, en esos años, conflictos regionales como la guerra de castas y la rebelión en la Sierra Gorda amenazaban con trascender al ámbito nacional. Las autoridades guanajuatenses trataron vehementemente de impulsar acciones de indole política y económica para controlar a la población serrana. El artículo aborda el proyecto para la construcción de un presidio en la población serrana de Atargea, el cual, además de desincentivar potenciales brotes de violencia, buscaría reactivar a la industria minera de la región.
\end{abstract}

Palabras clave: Atargea, clase política Guanajuatense, Guanajuato, presidio, revoluciones europeas, Sierra Gorda.

Enviado a dictamen: 16 de julio de 2009

Aprobación: 12 de octubre de 2009

Revisiones: 2

Carlos Armando Preciado de Alba, doctor en Historia por El Colegio de Michoacán, A. C., Profesor-Investigador de la Universidad de Guanajuato, temas de especialización: historia política, historia social, historia del siglo XIX. Correo electrónico: armandopre@hotmail.com; armandopre@quijote.ugto.mx.
Abstract: This article connects the establishment in 1848 of a presidio at Atargea, in Guanajuato's Sierra Gorda, $t$ o elite fears of social dissolution. Guanajuato officials worried that the recent outbreak of rebellion in the Sierra Gorda mirrored the contemporaneous Caste War in Yucatán and Europe's Revolution of 1848. To meet that threat, the state government conceived the presidio as an instrument of a larger project aimed at integrating the Sierra Gorda into the established order. The presidio was to contain popular violence through armed force, but also to reactivate the mining industry in the region. Hence the presidio was to supply a political and economic antidote to the spreading contagion of unrest.

Key words: Atargea, politics class Guanajuatense, Guanajuato, presidio, European revolutions, Sierra Gorda.

\section{Planteamiento e intenciones}

E experimentado político Luis Gonzaga Cuevas publicó en 1851 un ensayo en el que hizo un balance de los primeros 30 años de la vida independiente de México. En él plantea que una de las principales características de las décadas previas había sido el rompimiento de los lazos de la religión con el poder público. Vaticinó que la política sería incapaz de reorganizar a la sociedad si pretendía excluir de ésta a los principios religiosos. Señaló el peligro que repre- 
sentaba la proliferación de revoluciones proletarias y criticó que diversos regímenes mexicanos se empeñaran en ser "grandes" sin conservar lo que se tenía, buscando de manera frenética "imitar ciegamente a otras naciones civilizadas". Alertó sobre el riesgo que implicaba en México la potencial influencia de estos movimientos, sobre todo a causa de lo heterogéneo de la población y el deseo de imitar a las naciones ilustradas (González, 1977: 237).

En efecto, las revoluciones de 1848 inquietaron a grandes sectores de la clase política nacional (Lida, 2002: 66). ${ }^{2}$ Una de las mayores amenazas que percibían políticos como Cuevas era que se atacaría uno de los principios más respetados: la propiedad. Ante este escenario, gran parte del personal político y de la élite económica visualizaban sólo dos caminos: anarquía o poder absoluto. México vivía bajo un régimen republicano, condición que podría aminorar los temores de una revolución de grandes proporciones; no obstante, Cuevas señalaba que ante el riesgo latente de las nuevas teorías políticas, se debería

[...] temblar y temer también que seamos arrastrados por doctrinas que han propuesto los mayores absurdos como realizables. En una nación como la nuestra, donde el poder del gobierno tiene tan pocos medios de represión y donde la clase ilustrada representa tan corto número cualquier extravío devastaría el país y le obligaría sin duda a pasar por toda clase de calamidades [...] (González, 1977: 29, 34 y 35).

Hacia la primavera de 1848, los editores del periódico El Universal — que se auto definió como "conservador"afirmaron que la revolución en Europa representaba los horrores de una completa anarquía que amenazaba con destruir lo establecido, así como los adelantos de la humanidad. En cambio, algunos periódicos de tendencias progresistas como El Monitor Republicano, El Siglo XIX y El Eco del Comercio, aplaudieron las noticias relativas al movimiento revolucionario en Francia. Sin embargo, con los eventos de mayo y junio de ese año, la actitud de todos los periódicos mexicanos se tornó en contra de las teorías sociales y las clases populares. En los meses siguientes, los términos "socialismo" y "comunismo" adquirieron tal connotación negativa, que la prensa utilizaba estas etiquetas para atacarse unos a los otros. Con los meses, la simpatía por la revolución fue reemplazada por un discurso de temor, condena y repudio a las movilizaciones populares, con persistentes referencias a la "anarquía" y al "comunismo" (Lida, 2002: 69-70 y Pani, 2001: 62-68). ${ }^{3}$

El propósito de este artículo es destacar algunas cuestiones relacionadas con lo anterior. La difusión de ideas socialistas y la presencia de refugiados europeos en el país fueron vistas por actores de diferentes tendencias políticas como una amenaza al orden social, en particular a la tranquilidad de la población indígena. Esto a diferencia de la receptividad que tuvieron las ideas emanadas de las revoluciones de 1848 en otros países latinoamericanos como Brasil, Colombia o Chile (Hobsbawm, 1998: 22 y Lida, 2002). ${ }^{4}$ Lo anterior puede explicarse por la situación de la guerra internacional que enfrentaba México. Asimismo, por si fuera poco, había conflictos regionales que amenazaban con trascender al ámbito nacional: la rebelión en la Sierra Gorda, la guerra de castas en Yucatán y el constante amago de los apaches en el norte del país. Ante esto, ila clase política guanajuatense percibió alguna amenaza por los potenciales impactos de las revoluciones europeas de finales de la década de 1840? ¿Tales eventos alertaron a los gobernantes y les hizo endurecer sus acciones para tratar de controlar a los grupos populares a partir de proyectos de índole económica o política? ¿Cuál fue la estrategia del gobierno de Guanajuato para controlar al movimiento armado en la Sierra Gorda y neutralizar nuevos brotes de violencia?

Moisés González Navarro afirma que cuando se controló en términos militares a los sublevados de la Sierra Gorda, el gobierno federal "pasó del temor, ante la arrolladora guerra de castas e invasiones de los bár- 
baros, a cierta tranquilidad cuando los indios fueron rechazados", ya que las autoridades consideraban que la naturaleza de los serranos podría "poner en combustión a toda la república, dada la heterogeneidad racial del país y sus tendencias contra la propiedad" (González, 1977: 43-44). Empero, es necesario cuestionar esta aseveración a los ojos de las autoridades guanajuatenses y analizar con mayor detalle los proyectos políticos y económicos que buscaron implementar en la región durante los siguientes años para ejercer mayor control y tratar de desincentivar nuevos levantamientos armados e incluso movimientos separatistas. ${ }^{5}$

\section{Búsqueda de la pacificación en la Sierra Gorda}

La rebelión en la Sierra Gorda durante las décadas de 1840 y 1850 es un proceso que se ha estudiado de manera parcial. Además de ser contados los investigadores que lo han abordado, suelen concentrarse en el análisis de la base social que protagonizó el conflicto, así como en los eventos armados y demás de índole militar (Corbett, 1997; González, 1977; Pérez, 1988; Reina, 1990 y Tutino, 1990). Este proceso tuvo importantes repercusiones no sólo en Guanajuato, sino que fue una preocupación constante en el ámbito nacional. Las reacciones y medidas que tomaron los gobiernos — tanto estatal como federal - al momento que comenzaron las hostilidades armadas, en septiembre de 1847, fueron encaminadas fundamentalmente al sometimiento de los sublevados. Para los propósitos de este artículo, será necesario concentrar el análisis del conflicto desde la óptica de las implicaciones que tuvo en la clase política guanajuatense.

Dicho de otra manera, este conflicto no se circunscribió al ámbito militar, tampoco a demandas para exigir reivindicaciones sociales. Su inicio no se remonta solamente a la segunda mitad de 1847, ni finalizó en mayo de 1849 tras la aprehensión y fusilamiento de Eleuterio Quiroz, líder de los sublevados en ese momento. A partir de 1849 , una vez que estuvo relativamente controlada la situación armada, los gobiernos estatal y nacional pretendieron pacificar la región a través de otros mecanismos que no implicaban necesariamente la violencia militar. En este sentido, la legislación generada en los distintos niveles de gobierno es abundante. Resulta esencial no perder de vista eventos similares en otras regiones - por ejemplo el caso de la "guerra de castas" en Yucatán- como referentes útiles para plantear nuestro problema, el cual consiste en indagar si el conflicto de la Sierra Gorda suscitó reacciones en la clase política guanajuatense que pudieron unificar a las facciones existentes en un afán por fortalecer su poder frente a “amenazas" de este tipo.

Desde el punto de vista estrictamente militar, la sublevación de la Sierra Gorda terminó el 5 de diciembre de 1849, tras el fusilamiento de Eleuterio Quiroz. No obstante, la victoria en las armas no tranquilizó a las autoridades; ni a las nacionales, ni a las estatales. Ya desde los primeros días de 1849, había corrido el rumor de que los serranos amagaban con atacar la ciudad de Guanajuato, ${ }^{6}$ posibilidad que urgió aún más a los políticos guanajuatenses para solucionar el conflicto armado. Entre las principales tentativas se pensó conceder indultos a los rebeldes; mas sería el propio aparato gubernamental quien se reservaría el derecho a determinar las poblaciones en que radicarían los que se acogieran a tal beneficio. Esto es, se había autorizado al gobierno del estado a que fundara poblaciones con el fin de "conservar la tranquilidad".

Uno de los primeros intentos se dio en febrero de ese año, cuando el diputado local Manuel Jorrín señaló la imperiosa necesidad de moralizar a los pobladores de la Sierra Gorda, pues - a su parecer - la moral era la que prescribía y dirigía las costumbres de los hombres; la población, la moral, las buenas costumbres y la educación eran la garantía que tenían los gobiernos para evitar que se perturbara la tranquilidad pública. Jorrín estaba convencido de que tal objeto se conseguiría a través del establecimiento de misiones semejantes a las que habían operado ahí desde la época virreinal. 
De este modo, pidió que como un primer paso para la pacificación se concediera una amnistía general a los sublevados y a quienes los habían auxiliado. ${ }^{7}$

Poco después de que se logró la aprehensión de Quiroz, el Congreso del Estado otorgó el título de villa al pueblo de San Luis de la Paz, "por los importantes servicios que había prestado durante esa sublevación", mientras que el general José López Uraga —uno de los artífices de este triunfo- fue declarado "ciudadano distinguido de Guanajuato". También se estableció por decretó el departamento de Sierra Gorda y el pueblo "Xichú de Indios" pasó a llamarse "villa Victoria". En otro decreto, los diputados locales ordenaron la reconcentración en "colonias" de los pobladores serranos a partir de otorgarles terrenos realengos de la región, y además asignaron un fondo de 20 mil pesos para la compra de más tierras particulares. Según esta legislación, los beneficiados no podrían enajenar, gravar o empeñar sus nuevas propiedades sin licencia del gobierno sino pasados diez años. También se autorizaron hasta diez mil pesos para subsistencia y útiles de labranza de estos agricultores y se exceptuaría a sus habitantes de las nuevas colonias de las alcabalas y pensiones directas durante 5 años, y de la mitad de este pago en los 3 siguientes (Decretos, 1851: 66-71). En los hechos, la aplicación de estos decretos fue prácticamente nula.

Desde los meses más álgidos del movimiento armado, el diputado Jacinto Rubio, quien se caracterizó por manifestarse con desprecio hacia los sublevados y a favor de un sometimiento de éstos a cualquier precio, dijo que "la casi incomprensible revolución de la Sierra de Xichú" presagiaba una terrible guerra de castas que amenazaba con la disolución completa del estado "más rico y feliz de la república", pues pululaban en los caminos y en las poblaciones "enjambres de bandidos que amenazan impune y constantemente las vidas y las propiedades de los honrados ciudadanos que abundan aún, por fortuna entre nosotros". ${ }^{8}$ Tiempo después, durante las discusiones sobre si el gobierno debería otorgar la amnistía y tierras a los serranos que se habían levantado en armas, Rubio pidió a sus compañeros diputados que se consideraran algunas restricciones para evitar que los principales beneficiarios de dichas reparticiones fueran precisamente los sublevados. Señaló además que las autoridades deberían de ser cuidadosas en cuanto a la cantidad de tierra a repartirse, pues se corría un grave peligro debido a que la complacencia del gobierno podría favorecer "la reprobada doctrina del comunismo, que tantos males ha causado en la Europa". ${ }^{9}$ La anterior es una de las alusiones más claras que se hayan detectado por parte de algún miembro de la clase política guanajuatense a los eventos revolucionarios europeos y a las potenciales repercusiones que éstos traerían al país.

\section{Proyecto de un presidio en Atargea}

En plena guerra contra Estados Unidos y poco tiempo después de que inició el levantamiento armado en la Sierra Gorda, Lorenzo Arellano, gobernador de Guanajuato, dio a conocer un proyecto para el establecimiento de un presidio en el distrito minero de Atargea, población serrana en donde se habían localizado algunos yacimientos de azogue, mineral con altas concentraciones de mercurio. Arellano argumentó que de este modo se buscaba librar a México del monopolio extranjero de aquella materia prima. La abundancia de este mineral — apuntó- traería "necesariamente su baratura y con ella vendría luego la explotación de muchas minas de plata paralizadas hoy por la carestía de un ingrediente tan necesario para su beneficio". Con la construcción del presidio se instalaría una línea militar para proteger a la producción de las minas de los sublevados. Por otra parte, se trataban de impedir los asaltos de las conductas de plata enviados desde Guanajuato hacia Puebla o Veracruz (Expediente, 1848: 4-6 y 10-11).

Elmercurio representaba una materia prima esencial en ese momento, ya que era indispensable para el beneficio de metales. Su monopolio por parte de la Corona española durante el periodo virreinal provocó que sólo pudiera importarse de Europa, lo cual condujo a una 
mínima producción en el territorio novohispano. Esta condición hizo que una vez que se obtuvo la independencia de España, las minas nacionales continuaran dependiendo del comercio trasatlántico para cubrir con las necesidades de azogue, cuyos precios se fijaban a partir de la especulación internacional (Flores, 1984 47). ${ }^{10}$ Por lo anterior, nuevos proyectos de exploración, explotación, producción y distribución de este mineral fueron cuestiones que se discutieron recurrentemente entre empresarios mineros, gobiernos locales y nacionales durante prácticamente todo el siglo XIX.

En este orden de ideas, los mineros guanajuatenses tuvieron pocos resultados efectivos, así que siguieron dependiendo de la compra de azogue a precios muy elevados. No obstante, sabían que en la Sierra Gorda existían yacimientos de este mineral, como lo evidenció un minucioso informe que a principios de 1844 elaboraron los ingenieros Ignacio Alcocer y Benito Herrera. En él, se detallaba la ubicación de las minas existentes, calidad y los costos de su producción. A pesar del potencial que implicaba la explotación de aquellos yacimientos, el informe señaló que al menos en un mediano plazo las utilidades no serían suficientes para evitar depender de su importación, pues las minas tenían poca profundidad y en ese momento no existían las condiciones para trabajarlas de manera sistemática. En contraste, otro informe realizado ese mismo año por los peritos facultativos Francisco Anda y Vicente Meana fue más optimista, ya que se refería a una "lisonjera expectativa de aquellos fundos", así que auguró que su trabajo traería a la industria minera gran utilidad y ventajas. ${ }^{11}$

A partir de agosto de 1846, luego que se restauró el sistema federal, algunos miembros de la clase política guanajuatense decidieron retomar el proyecto de la explotación sistemática de tales minas, pues estaban convencidos que con el nuevo régimen tendrían mayores beneficios en términos fiscales. Arellano se mostraba seguro de la viabilidad del proyecto y en repetidas ocasiones trató de convencer a unos escépticos legisladores de que no sería una carga excesiva para el erario estatal el sostenimiento de los presos que se trasladaran a aquel lugar. Desde febrero de 1847 insistió que las actividades mineras en que se emplearían a los reos serían suficientes para su manutención. Para echar a andar el proyecto, Arellano propuso pagar hasta 40 mil pesos para el avío de las minas en cuestión; tal cantidad se tomaría de fondos del ramo de Instrucción Pública (Expediente, 1848: 45-47). ${ }^{12}$ La inversión esperaba recuperarse a partir de los dividendos que generase la extracción del azogue, de suerte que poco a poco se restituyera el capital de la Instrucción Pública. Sin embargo, poco tiempo después el plan se vino abajo, pues el referido fondo se utilizó en el pago de un préstamo forzoso que exigió el gobierno nacional para atender las exigencias de la guerra con Estados Unidos. Ante esta seria eventualidad, Arellano pidió al Congreso del Estado que autorizara tomar los $40 \mathrm{mil}$ pesos para el avío de la minas de otro fondo del erario estatal (Expediente, 1848: 4-8).

En febrero de 1848, ante la insistencia del gobernador, los diputados locales indicaron a Arellano que antes de que el poder Legislativo pudiera emitir alguna resolución al respecto, requerían un informe circunstanciado de las bases sobre las que se realizaría el avío, del reconocimiento de los peritos y de los fondos precisos de donde habrían de tomarse las cantidades solicitadas. En seguida, Arellano pidió a la Diputación de Minería una copia del informe de la situación y potencialidades de los yacimientos que se encontraban en Atargea. Además de remitirle los resultados del trabajo realizado por Anda y Meana 4 años atrás, se entregaron a Arellano dos informes más, uno realizado por el empresario español Leopoldo Vidal y otro por Pío Salgado, miembro de propia Diputación de Minería. Ambos documentos referían de halagüeñas expectativas para la explotación minera. Sin embargo, no fue considerado el informe hecho por Alcocer y Herrera, quienes advertían mayor cautela en cuanto a los posibles resultados. Tras el análisis de estos documentos el gobernador envió a la Legislatu- 
ra local a otra propuesta para concretar el proyecto. No obstante, en mayo de 1848 la comisión de Justicia del Congreso del Estado dictaminó que se pidieran a Arellano aún más datos para que pudiera "despacharse definitivamente el asunto". ${ }^{13}$

El proyecto de Arellano estipulaba además, que los dueños de los minerales pagarían desde 3 hasta 4 reales diarios por preso: uno para alimentos y vestuario, otro para el pago de sus custodios y uno más para un fondo de ahorro. En el presidio trabajarían por periodos de 6 a 24 meses, vagos, jugadores y "cualesquiera clase de hombres perjudiciales a la sociedad". En efecto, la parte medular de la propuesta del gobierno del estado no se limitaba a la explotación minera. Arellano tenía en mente "solucionar" el conflicto social en la región a través de un programa de colonización. En julio de 1848 escribió al Ministro de Relaciones para explicarle que:

[...] Los únicos terrenos que en este Estado existen a propósito para colonización son en mi concepto los que se hallan comprendidos dentro de su demarcación en la Sierra nombrada de Xichú. Ellos [...] se encuentran hoy habitados por indígenas cuyos hábitos y falta de educación los tiene sumergidos en la miseria y la barbarie, que es lo que con frecuencia los impele a turbar el orden público y a querer vivir sólo del robo y el pillaje. Los terrenos de que hablo son de propiedad particular, mas sin embargo, no juzgo difícil pudieran conseguirse, mediante una indemnización aquellos que fueran necesarios para colonizarse. De esta manera la civilización y moralidad se difundiría entre aquellos moradores que el frecuente trato y comunicación con los colonos, se dedicarían al trabajo y a la industria para ganar honradamente su subsistencia y en suma, disfrutando los bienes de una sociedad bien ordenada dejarían las costumbres perniciosas en que los tiene sumergidos su barbarie, y que actualmente se hacen resentir en varios puntos, no sólo de este Estado, sino en otros de los de Querétaro y San Luis Potosí $[. . .]^{14}$
Lo dicho por Arellano en este extenso fragmento nos ejemplifica la opinión que tenían gran parte de los políticos de aquellos años con relación a las comunidades indígenas. No se trataba solamente de acabar con el movimiento armado, sino de "integrar" a estos sectores a los proyectos modernizadores, tanto económicos como políticos, que la nación necesitaba. De esta manera, creía que el establecimiento de un presidio ayudaría a la población serrana, pues modificaría las costumbres "semibárbaras que los inclinan al robo y a otros delitos, a la ociosidad y a otros vicios, entre los que el de la embriaguez es más dominante", por lo que se crearía un cerco militar para proteger a las minas de posteriores levantamientos en la región. Arellano estaba convencido de que "el trabajo moraliza a los hombres, y la ocupación continua los distrae de los proyectos funestos para ellos y para la sociedad" (Expediente, 1848: 14-15). ${ }^{15}$

El l de diciembre de 1849 comenzó en el Congreso del Estado la discusión en lo general del proyecto sobre el establecimiento del presidio. Según la propuesta del gobierno, a dicho sitio serían enviados todos los reos sentenciados a la realización de obras públicas y trabajos forzados de 6 meses en adelante. El gobierno formaría a la brevedad, un presupuesto de gastos que estimara necesarios, el cual debía ser aprobado por el pleno del Congreso local o por la Diputación Permanente. El diputado Jacinto Rubio tomó la palabra. Se pronunció renuente, pues aunque el espíritu de éste le parecía una buena idea, era altamente riesgoso que el propio gobierno se convirtiera en especulador de una empresa minera. Rubio esgrimió un par de argumentos para explicar su rechazo. En primer lugar, criticó que el gobierno del estado actuase también como empresario, pues tal condición se hallaba

[...] en evidente contradicción con las doctrinas de todos los publicistas que al aconsejar los verdaderos medios de proteger las empresas industriales de un país, reprueban el que los gobiernos intenten hacerlo descendiendo para ello a la clase de negociantes [pues 
el aparato del Estado] se lastimaría poniéndose al nivel de las personas con quien debe contratar en calidad de aviador, y se menoscaba el prestigio de que debe estar rodeada su autoridad para ejercerla con una verdadera libertad e independencia $[\ldots]^{16}$

Así pues, Rubio se remitió a uno de los principios esenciales de la doctrina liberal según el cual, a pesar de que una de las obligaciones vitales del Estado era la defensa de la propiedad y la preservación por todos los medios legítimos a su alcance de los derechos individuales del hombre, no podría intervenir de forma directa en el desarrollo de las empresas económicas. En segundo lugar, señaló los riesgos que implicaba la industria minera, pues sus resultados siempre eran inciertos, ya que existían variables y circunstancias fortuitas que no siempre podían preverse. En este sentido, apostar los fondos públicos al éxito de un negocio de tales características implicaría consumir las rentas estatales sin tener la certeza de que éstas podrían recuperarse. Joaquín Ladrón de Guevara, presidente del Congreso en ese momento, se unió a las observaciones de Rubio y también se opuso a la aprobación del proyecto.

Los diputados Julio Pedroza y Vicente López defendieron el proyecto. Pedroza dijo que si bien eran válidas las observaciones acerca de los principios de un buen gobierno que adujo Rubio, éstos no debían aplicarse a rajatabla en todos los casos, sin considerar a las circunstancias particulares que pudieran presentarse. En cuanto al temor de que fuese indefinido el gasto para la empresa, dijo que esperaba "sacarse provecho de los presidiarios"; agregó que no se trataba de facultar al gobierno para que gastara a discreción en el proyecto, sino que únicamente se le autorizaría para invertir una cantidad determinada en el mantenimiento del presidio, ya que para los gastos que éste demandara en su conservación, el mismo gobierno debería de formar los correspondientes presupuestos y pasarlos a la aprobación del Congreso. Aún con estas discrepancias, tras una votación, la mayoría de los legisladores aprobaron en lo general el proyecto de Arellano.

Después de más de dos años de trabajos del gobernador, la anuencia del Congreso del Estado a su propuesta fue sólo una victoria pírrica. A finales de enero de 1850 solicitó licencia a la Legislatura local para separarse de su cargo; el motivo que mencionó fue la realización de un viaje al departamento de Sierra Gorda para ultimar los detalles y echar a andar el proyecto una vez que los diputados lo habían avalado. ${ }^{17}$ Además de las razones expresadas por Arellano, su viaje a aquella región obedeció sin duda a que el gobernante buscaba dar una señal al resto de la clase política y de la élite económica de que la Sierra Gorda se encontraba en paz y que era perfectamente factible emprender actividades económicas. Arellano regresó a la ciudad de Guanajuato a mediados de febrero.

Pocos días después Rubio y Ladrón de Guevara convencieron al pleno de los legisladores locales de lo urgente que era que el Ejecutivo estatal les presentara el presupuesto de los gastos que demandaba el establecimiento y conservación del presidio. De hecho, propusieron que se enviara a Arellano una nota en la que se le fijaba un plazo de 15 días. El "exhorto" advertía que de no contar con el requerimiento, no podría despacharse a la comisión de Hacienda el dictamen relativo a la aprobación del presupuesto general. Un par de días después Arellano respondió que el presupuesto no estaría listo en el plazo fijado, ya que los agentes del gobierno aún se encontraban reuniendo los datos necesarios. La exigencia de los diputados fue calificada por Arellano como "una ocurrencia peregrina", y argumentó que para ninguna de las minas aviadas en que había tenido participación el gobierno de Guanajuato desde años atrás, se solicitó como prerrequisito la elaboración de presupuestos por parte de éste (Arellano, 1851: 22-23). ${ }^{18}$

Conforme pasaron las semanas, las relaciones entre Ejecutivo y Legislativo estatales se tensaron aún más. Transcurrieron los meses de marzo y abril sin que Arellano remitiera al Congreso el requisito exigido. El ll de 
mayo de 1850 los diputados guanajuatenses aprobaron el presupuesto para el año económico 1850-1851. En el mismo decreto ordenaron la suspensión del proyecto del presidio en Atargea hasta que las autoridades respectivas entregaran los cálculos requeridos. Asimismo, se derogó la autorización al gobierno del estado para que se erigieran poblaciones en los puntos de la Sierra Gorda que juzgara oportuno con el fin de conservar la tranquilidad en aquel territorio (Decretos, 1851: 69-71 y 111-131). Arellano no perdió tiempo para recriminar a los legisladores su decisión de restringir las medidas que ellos mismos habían aprobado meses antes. Para él la actitud de los diputados era incongruente, pues el gobierno "no podía formar este presupuesto sin datos; no podía adquirir estos datos sin hacer algún gasto; no podía hacer este gasto sin la autorización del decreto [...] ¿Cómo, pues —encaró Arellano a los legisladores — ha podido llenar este deber, quitados los únicos medios de conseguirlo?" (Arellano, 1851: 22-23).

Con gran desilusión por el proceder de los legisladores, Arellano solicitó licencia para separarse de su cargo durante 4 meses. Ésta le fue concedida por el Congreso local a finales del mismo mes de mayo. ${ }^{19}$ Debido a la enfermedad del vicegobernador Jacinto Rodríguez, Arellano fue substituido por el consejero Mariano Leal y Araujo, quien no insistió en el asunto del presidio.

Todavía en enero de 1851 —en las postrimerías de su régimen - encontramos a un Arellano empeñado en resolver el conflicto en la Sierra Gorda. Manifestaba que aún con la relativa paz en la región, seguían "fermentando los diversos elementos de que se compuso", ya que las pasiones de la venganza seguían despiertas, los vicios de la ociosidad y de la embriaguez no habían disminuido y, en general, las condiciones de aquellos pobladores no habían mejorado en lo absoluto (Arellano, 1851: 21). En uno de sus últimos discursos como gobernador hizo énfasis en los riesgos generados por los movimientos populares y la difusión de las doctrinas socialistas. Señaló que la inmoralidad crecía día a día en todas las clases de la sociedad y alertó a la clase política sobre aquellas:
[...] ideas y doctrinas de los que por antífrasis se llaman socialistas, sin embargo de haber sido combatidas victoriosamente en Europa, hoy se introducen en la república; porque desgraciadamente se hacinan en ella los elementos de división y de desorden, los de una conflagración general, en cuya explosión, si no se contiene, irán hasta sus autores (Arellano, 1851: 20).

Ante este panorama Arellano se convencía de la necesidad de:

[...] prevenir el modo de cortar la inmoralidad que se ha difundido en todas las clases, no menos que el fuego revolucionario que comienza a encenderse bajo los principios más antisociales, pero más halagüeños para la clase ignorante y menesterosa (Arellano, 1851: 20).

Luego de los momentos más difíciles provocados por la guerra contra Estados Unidos y el conflicto armado en la Sierra Gorda, se encuentra a Arellano todavía desesperado por alcanzar el orden, por hacer que la autoridad se erigiera como protagonista de la vida pública. Estaba convencido de que la incapacidad de las autoridades por ejercer el poder había provocado "la desmoralización, la desobediencia y el desenfreno", lo cual desencadenaría el desorden y la anarquía. En este sentido, el gobernador se quejó ante el Congreso local por la manera en que el aparato estatal aplicaba la justicia y por la forma como éste designaba a las autoridades. Por lo anterior pidió a los diputados que trabajaran para elaborar códigos de justicia precisos y reformar la Constitución local con la finalidad de otorgar mayores atribuciones para que el Ejecutivo participara en tales procesos.

Conforme pasaron los meses el furor de la clase política por el riesgo que implicaban los eventos en la Sierra Gorda fue disminuyendo. En febrero de 1851 tomó posesión de la gubernatura Octaviano Muñoz Ledo, quien abandonó el proyecto arellanista de establecer un presidio en Atargea. Sin embargo, al igual que su antecesor estaba convencido de que la potestad en la 
aplicación de las leyes correspondía — con absoluta independencia de los poderes Legislativo y Ejecutivoal Supremo Tribunal de Justicia y a los jueces estatales. De ahí que la libertad en el ejercicio de la facultad de juzgar, debía ser la primera garantía para los encargados de administrar justicia. Según la visión de estos políticos letrados, la pronta y recta administración de justicia en el ramo criminal era de una importancia reconocida, pues la conservación del orden, el mantenimiento de la tranquilidad pública y el pronto castigo de los delincuentes, inspiraría la confianza de la población, generaría credibilidad y apuntalaría la legitimidad de las instituciones de gobierno.

El conflicto armado en la Sierra Gorda nos brinda la oportunidad de profundizar en algunos rasgos de la ideología de los gobernadores Arellano y Muñoz Ledo. Ambos letrados dieron muestras de su identificación con la doctrina liberal. Arellano, propuso al Congreso del Estado trabajar en torno a 3 grandes ejes para impulsar la economía y la paz social de los pobladores serranos. Primero, se promovería el laborío de las minas poco conocidas y explotadas; en tal sentido, cabe suponer su pretensión de que el presidio en Atargea no sólo sirviera para aumentar la población y los recursos materiales de la región, sino que sería una garantía de seguridad para los inversionistas particulares, ya que el gobierno mantendría una fuerza armada constante y permanente.

El segundo eje tenía que ver directamente con la población local: corregir hábitos dañinos como la ociosidad y el alcoholismo. Lo anterior se conseguiría "incentivando" el amor al trabajo a partir de "severos castigos" para corregir los referidos vicios. Arellano era conciente del conflicto político que entrañaba la Sierra Gorda. Para él, "las pasiones de la venganza" continuaban despiertas, pues las circunstancias de los pobladores serranos no habían mejorado. Por tanto, era responsabilidad del aparato estatal dar seguimiento y aportar soluciones; de lo contrario, se corría el riesgo de un nuevo estallido de violencia a gran escala (Arellano, 1851: 21).
Por último - y es aquí en donde encontramos el meollo del liberalismo de Arellano- proponía subdividir la mayor cantidad posible de la propiedad territorial. Esto se conseguiría por medios indirectos, uno de ellos era declarar libre de alcabala la venta de haciendas que se dividiera en diversas fracciones destinadas a sujetos distintos. Asimismo, pedía que se autorizara al gobierno del estado para que pudiera utilizar los fondos de Instrucción Pública en la compra de fincas rústicas en los departamentos de Allende y de Sierra Gorda, enajenándolas en parcelas destinadas a los serranos más necesitados. Arellano comparaba la situación agraria de la Sierra Gorda con el resto de los departamentos del estado de Guanajuato. Señaló que a pesar de la mayor densidad de población en estos últimos, se notaba en ellos más afecciones por el orden que en la región serrana. El gobernador atribuyó esta característica al hecho de la subdivisión de la propiedad territorial, pues aquellos pobladores que lograban poseer alguna propiedad se convertían en amantes del orden y de la paz, y por ésta expondrían aún su misma vida (Arellano, 1851: 23-25).

Para prevenir un nuevo levantamiento en la Sierra Gorda, Muñoz Ledo insistió en que se debía vigilar a las autoridades y a los caciques locales. De este modo, se impediría que ejercieran actos de opresión contra los pobladores. Alejándose del proyecto arellanista, instó para que se dejase a los serranos la libertad para proporcionarse la subsistencia por los medios honestos de trabajo que ellos eligiesen, así se tratara de actividades agrícolas, mineras, pecuarias, forestales o artesanales.

Mucho más atento que Arellano a las condiciones de vida de los serranos - seguramente por el fin de la guerra contra Estados Unidos y porque el levantamiento armado en la Sierra Gorda estaba controlado- Muñoz Ledo exigió que cesaran las levas y que se eximiera a las poblaciones serranas del contingente de sangre; práctica que además de desintegrar muchos núcleos familiares, provocaba el abandono de las actividades primarias de los afectados. No abundó demasiado en el tema del 
fraccionamiento de las grandes propiedades, pero se pronunció a favor de los derechos de los trabajadores frente a constantes despojos y bajos salarios a los que eran objeto por los propietarios. En este sentido, propuso que se instrumentaran mecanismos de vigilancia tales como la presencia de agentes en algunos puntos más convenientes de la Sierra, lo que haría que la tranquilidad pública se conservara o, cuando menos, que no hubiera motivo fundado para su alteración (Muñoz, 1852: 70-71).

\section{Consideraciones finales}

Aún es posible encontrar trabajos historiográficos que sugieren - al menos de manera implícita- que a los mexicanos que vivían hacia mediados del siglo XIX no sólo los separaban miles de leguas de Europa, sino que además mediaba entre ambos continentes un desconocimiento mutuo de los eventos acaecidos. Si bien es cierto que este artículo se concentra en un sector de la clase política, se demostró que las revoluciones ocurridas en el viejo continente a partir de 1848 permearon de manera considerable y realmente llegaron a causar temores e inquietud en dicho sector debido a que fueron percibidas como un peligro para el orden social. Esto coincidió con la insurrección en la Sierra Gorda, conflicto regional en el que se vio inmiscuida la entidad guanajuatense. Ante tal evento fue claro el temor de las autoridades estatales, quienes impulsaron un proyecto para la construcción de un presidio en Atargea a partir del cual no sólo se buscaría aprovechar su potencial minero, sino sobre todo, reprimir futuros brotes de violencia.

En la sección introductoria presentamos el planteamiento de González Navarro, quien afirma que bastó a las autoridades con someter militarmente a los sublevados para sentir relativa tranquilidad. No obstante, al haber concentrado el análisis en actores políticos regionales se tambalea el argumento de González, pues resulta claro que un control militar no bastaba para tranquilizarles. Consideraban esencial la implan- tación de proyectos económicos insertos en un marco ideológico netamente liberal con el fin "incorporar" a la población serrana en políticas modernizadoras. ${ }^{20}$

Aún con las expectativas más o menos favorables que brindaban las exploraciones científicas, no logró concretarse algún proyecto de explotación intensiva de las minas ubicadas en la Sierra Gorda. Sumados a los eventos y pugnas políticas que se han explicado a lo largo del texto, debemos señalar la existencia de al menos dos condiciones estructurales que desalentaron la inversión tanto pública como privada en aquella región. La primera de ellas tiene que ver con la situación geográfica. Existe una lejanía significativa con los distritos mineros de Guanajuato y de La Luz, la cual, aunada al escarpado relieve serrano y a las deficientes vías de comunicación, harían que se elevaran de manera exponencial los costos de exploración, extracción y traslado a las haciendas de beneficio de la ciudad de Guanajuato.

En segundo lugar, la Sierra Gorda cuenta con características socioeconómicas y culturales que históricamente han marcado un fuerte contraste con el resto de la entidad. Su población, mayoritariamente de origen indígena, sistemáticamente se negó al sometimiento por parte de las autoridades coloniales y posteriormente mexicanas. Por lo anterior, sumado a lo inaccesible del terreno, esta región se mantuvo como un enclave de refugio indígena y como un potencial foco de inestabilidad social.

\section{Notas}

${ }^{1}$ La referencia completa de la obra que cita González Navarro es: Cuevas, Luis, 1851, El Porvenir de México o juicio sobre su estado político en 1821 y 1851, Ignacio Cumplido, México.

${ }^{2}$ En las fuentes diplomáticas son escasas las referencias a los eventos de 1848. Mientras tanto, la correspondencia particular sí cuenta con menciones al respecto. José María Luis Mora -en ese momento ministro plenipotenciario en Inglaterra- se pronunció en contra de "la al- 
teración universal del orden y la paz". Lida sugiere que quizá fue Mora el primero en enviar informes al gobierno mexicano de lo ocurrido en Francia.

${ }^{3}$ Los mismos periódicos que antes del estallido de la revolución admiraban la "política sabia y prudente de Luis Felipe", y que reconocían que bajo su protección Francia se había convertido en una de las primeras naciones del mundo, celebraron el inicio del movimiento en febrero de 1848. Érika Pani señala que hasta que las noticias de los sucesos del 23 al 26 de junio no llegaron a México, los comentarios editoriales de estos periódicos fueron siempre favorables a la revolución. Esta aparente flexibilidad ideológica evidencia que los distintos grupos políticos coincidían en cuanto a la conveniencia de un proyecto "liberal burgués", defensor de la propiedad y temeroso de los desordenes provocados por las clases populares.

${ }^{4}$ Para Eric Hobsbawm la revolución de 1848 fue el primer movimiento político potencialmente mundial cuya influencia directa se percibió en algunas naciones de América Latina como Brasil y Colombia. Sólo después de la Revolución de Ayutla, los liberales mexicanos comenzaron a considerar que los ideales de 1848 podrían contribuir no sólo al progreso de la humanidad, sino también al éxito del proyecto político liberal.

${ }^{5}$ Un manifiesto firmado en Atargea el 22 de septiembre de 1848 señala que tras haberse reunido las autoridades civil, eclesiástica y militar y demás vecinos de aquella población, vislumbraron "una borrasca espantosa que tiende a su aniquilamiento". Por lo anterior, exigieron que se reconociera a la Sierra Gorda como "un estado soberano, libre e independiente". Archivo General del Estado de Guanajuato (en lo sucesivo AGEG), Colección de Impresos Textuales, exp. 10, cajón 1 .

${ }^{6}$ Arellano a Francisco Martínez de Lejarza, Guanajuato, 15 de febrero de 1849, en AGEG, Fondo Secretaría de Gobierno, Sección Secretaría de Gobierno (en lo sucesivo AGEG-SG), Serie Archivo, caja 221, año 1849, exp. 2.

${ }^{7}$ Los diputados estatales no legislaron para la fundación de misiones. No obstante, apoyaron una propuesta rea- lizada por el gobierno federal en el sentido de que los estados involucrados en el conflicto (Guanajuato, Querétaro y San Luis Potosí) deberían apoyar en términos monetarios el establecimiento de misiones. Archivo Histórico del Congreso del Estado de Guanajuato, Sección Actas de Sesiones (en lo sucesivo AHCEG-AS), libro de 1849, sesión del 21 de febrero de 1849.

${ }^{8}$ AHCEG-AS, libro de 1849, sesión del 20 de enero de 1849.

${ }^{9}$ AHCEG-AS, libro de 1849, sesión del 30 de noviembre de 1849.

${ }^{10}$ Hacia 1835, la Casa Rothschild de Inglaterra monopolizaba tal producto. Ese año el quintal de azogue llegó a cotizarse en Veracruz en 135 pesos; mientras que una década atrás, la misma cantidad costaba 50 pesos.

"AGEG-SG, caja 186, año 1844, exp. 3 y caja 213, año 1848, exp. 3.

${ }^{12}$ La duración del avío de las minas sería por un tiempo indeterminado, con una participación de 12 barras para el estado de Guanajuato y las 12 restantes para los aviados.

${ }^{13}$ AGEG-SG, caja 213, año 1848, exp. 3 y AHCEG-AS, libro de 1848, sesión del 27 de mayo de 1848.

${ }^{14}$ AGEG-SG, Serie Secretaría de Gobierno, caja 217, año 1848, exp. 1 .

${ }^{15}$ Arellano a Francisco Martínez de Lejarza, Guanajuato, 15 de febrero de 1849, en AGEG-SG, Serie Archivo, caja 221, año 1849, exp. 2.

${ }^{16}$ AHCEG-AS, libro de 1849, sesión del 1 de diciembre de 1849.

${ }^{17}$ Con relación a esta visita, Arellano señaló que "su sentimiento fue grande al palpar la miseria que rodeaba a todos", lo que reafirmó su convicción por la necesidad de materializar el proyecto. AGEG-SG, Serie Secretaría de Gobierno, caja 228, año 1850, exp. 12.

${ }^{18}$ AHCEG-AS, libro de 1850, sesiones del 20 y 23 de febrero de 1850.

19 AGEG-SG, Serie Secretaría de Gobierno, caja 228, año 1850, exp. 12.

${ }^{20}$ Por políticas modernizadoras entiendo a los ideales liberales, a las formas en que las élites latinoamericanas 
abrazaron las causas del liberalismo económico y social, el individualismo y la creación de ciudadanía, así como el libre mercado de tierras y fuerzas de trabajo y la libre circulación de ideas. Para conocer más de estas concepciones: Escobar, 2002.

\section{Bibliografía}

Arellano, Lorenzo (1851), Memoria que el gobernador Lorenzo Arellano del estado de Guanajuato leyó el día lo de enero de 1851, en el salón del Honorable Congreso para dar cumplimiento en lo prevenido en las constituciones general y particular e informar sobre los diversos ramos de la administración pública, México: Imprenta de Cumplido.

Corbett, Barbara (1997), "La política potosina y la guerra con Estados Unidos”, en Josefina Z. Vázquez (coord.), México al tiempo de su guerra con Estados Unidos (1846-1848), México: F.C.E./Colmex/S.R.E., pp. 455-480.

Decretos expedidos por el Séptimo Congreso Constitucional del Estado de Guanajuato, en los años de 1849 y 1850, (1851), Guanajuato: Impresos por Félix Conejo.

Escobar, Antonio, Falcón Romana y Raymond Buve (comp.) (2002), Pueblos, comunidades y municipios frente a los proyectos modernizadores en América Latina, siglo XIX, San Luis Potosí: El Colegio de San Luis/C.E.D.L.A.

Expediente instruido sobre el establecimiento de un presidio en Atargea, para el laborío de minas de azogue, proyectado por el Gobierno del Estado de Guanajuato, (1848), Tipografía de Juan E. Oñate, Guanajuato.
Flores Clair, Eduardo y Cuauhtémoc Velasco (1984), "Minería y poder político en México. 1770-1856", en Historias, núm. 5, enero-marzo, p. 33-51.

González Navarro, Moisés (1977), Anatomía del poder en México (1848-1853), México: El Colegio de México

Hobsbawm, Eric (1998), La era del capital, 1848-1875, Barcelona: Crítica.

Lida, Clara (2002), "The Democratic and Social Republic and its Repercussions in the Hispanic Word", en Guy Thomson (editor), The European Revolutions of 1848 and the Americas, London: Institute of Latin American Studies, pp. 46-75.

Muñoz Ledo, Octaviano (1852), Memoria del gobierno del estado de Guanajuato presentada a su Honorable Legislatura en Io de enero de 1852, México: Imprenta de Lara.

Pani, Érika (2001), Para mexicanizar el Segundo Imperio: el imaginario político de los imperialistas, México: El Colegio de México/Instituto Mora.

Pérez Bolde, Alfredo (1988), "Notas sobre la rebelión de Sierra Gorda”, en José Arturo Salazar (coord.), Guanajuato: evolución social y política, León, México: El Colegio del Bajío.

Reina, Leticia (1990), "La rebelión campesina en Sierra Gorda, 1847-1850", en Friedrich Katz (compilador), Revuelta, rebelión y revolución. La lucha rural en el México del siglo XVI al siglo XX, México: Ediciones ERA, tomo 1, pp. 242-266.

Tutino, John (1990), De la insurrección a la revolución en México. Las bases sociales de la violencia agraria 1750/1940, México: Ediciones ERA. 